\title{
Changes in prevalence and perinatal outcomes of congenital hydrocephalus among Chinese newborns: a retrospective analysis based on the hospital-based birth defects surveillance system
}

Ling $\mathrm{Yi}^{1+}$, Chaomin Wan ${ }^{2+}$, Changfei Deng ${ }^{1}$, Xiaohong $\mathrm{Li}^{1}$, Kui Deng ${ }^{1}, \mathrm{Yi} \mathrm{Mu}^{1}$, Jun Zhu ${ }^{1}$, Qi Li ${ }^{1}$, Yanping Wang ${ }^{1}$ and Li Dai ${ }^{*}$

\begin{abstract}
Background: Little is known about the epidemiology of congenital hydrocephalus $(\mathrm{CH})$ in China. This study aimed to depict recent changes in $\mathrm{CH}$ prevalence and perinatal outcomes of the affected newborns.

Methods: Data were obtained from the Chinese Birth Defects Monitoring Network (CBDMN), which collects demographic information on all newborns above 28 weeks of gestation, and clinical information on neonates with congenital anomalies. CH cases delivered during 2005-2012 were analyzed. Poisson regression was used to calculate prevalence ratios (PR) and 95\% confidence intervals, and linear chi-square test was used to examine time trend of $\mathrm{CH}$ prevalence.
\end{abstract}

Results: Five thousand two hundred forty-five isolated and 1245 associated $\mathrm{CH}$ cases were identified among 10,574,061 newborns, yielding the prevalence of 4.96, 1.18 and 6.14 per 10,000 births for the isolated, associated and overall hydrocephalus, respectively. The annual prevalence of $\mathrm{CH}$ presented a decreasing trend (from 7.52 to 5.98 per 10,000 births, $P<0.001$ ). Higher prevalence was found in both younger ( $<20$ years, PR: 1.81, 95\% Cl: 1.56-2.10) and older ( $\geq 35$ years, PR: $1.48,95 \%$ Cl: 1.36-1.61) maternal-age groups in comparison with the maternal-age group of 20 to 24 years. Higher prevalence was also found in infants born to mothers resided in rural areas, male infants, and multiple births. Of non-aborted infants with congenital hydrocephalus, 38.11\% were born with low birth weight, 37.53\% were preterm birth, and 20.69\% died within 7 days after birth.

Conclusions: Our findings present a relatively high prevalence and poor perinatal outcomes of $\mathrm{CH}$ in China, which can serve as a baseline for future study.

Keywords: Congenital hydrocephalus, Birth defects, Prevalence, Perinatal outcome, Newborns

\footnotetext{
* Correspondence: daili@scu.edu.cn

${ }^{\dagger}$ Equal contributors

${ }^{1}$ National Center for Birth Defects Monitoring, West China Second University

Hospital, Sichuan University, Sec.3 No.17, South RenMin Road, Chengdu,

Sichuan 610041, China

Full list of author information is available at the end of the article
} 


\section{Background}

Congenital hydrocephalus $(\mathrm{CH})$ is a group of neurological disorders caused by various reasons that all result in imbalance between the production and absorption of cerebrospinal fluid (CSF) [1]. The main characteristics are the accumulation of CSF in the cranial cavity and ventricular dilatation [2]. Besides a strong genetic background, prematurity, infection, and intracranial structural malformations such as neural tube defects (NTDs) and aqueduct stenosis can give rise to $\mathrm{CH}$ [3-6]. $\mathrm{CH}$ resulting from brain anomalies always have poor prognosis, particularly high neonatal fatality rate and impaired mental development. Although surgical interventions are widely used to improve the health of the affected children, life-long treatment or multidisciplinary care are needed. The prevalence of $\mathrm{CH}$ varied between 4 and 12 per 10,000 births [7-13]. The reported prevalence of $\mathrm{CH}$ in provinces of China ranged from 6.9 to 9.2 per 10,000 births [11-13]. Based on data from the Chinese Birth Defects Monitoring Network (CBDMN), an overall prevalence rate of 7.03/10,000 and an upward trend were observed during 1996-2004 [14]. Health care services for women and children have been improved considerably in China over the recent decade [15]. In particular, lots of medical institutions have been established to provide prenatal screening and diagnosis services for pregnant women since the National Regulation on the Administration of Prenatal Diagnosis Techniques took effect in 2003 [16], which led to the improvement of prenatal diagnosis and an increase in termination of pregnancies with severe birth defects. These changes had a great impact on the birth prevalence of certain birth defects in China, such as NTDs and Down syndrome [17, 18]. However, whether $\mathrm{CH}$ prevalence was affected by changes of the policy remains unknown. This study aimed to investigate recent changes in the prevalence of $\mathrm{CH}$ and perinatal outcomes of the affected neonates based on newly updated CBDMN database.

\section{Methods}

\section{Study subjects}

Data on $\mathrm{CH}$ cases and newborns in the study were abstracted from CBDMN, a nationwide hospital-based birth defects surveillance program in China, with monitoring period from 28 weeks of gestation to 7 days after birth. The procedure of data collection, case ascertainment and data quality management has been described in detail elsewhere [19, 20]. In brief, a threelevel (county, province, and central) surveillance network and corresponding expert groups were established to perform routine data collection. Summary data of all births (live or stillbirths $\geq 28$ weeks of gestation) and information of individual birth defect cases were collected with standardized forms by hospital staff and then checked by expert groups at each level. In addition, an independent retrospective survey was organized to identify underreporting of birth defects and inaccuracies in data, and database was subsequently updated prior to annual reporting. CBDMN adopts the same criteria of $\mathrm{CH}$ cases as described by the International Clearinghouse for Birth Defects Surveillance and Research (ICBDSR) [21]. $\mathrm{CH}$ cases characterized by dilatation of the cerebral ventricles and diagnosed prenatally or within the first week of life were included, and cases caused by premature birth, intraventricular haemorrhage or secondary to NTDs were excluded. We searched the CBDMN database from January 2005 to December 2012 for all births with a diagnosis of hydrocephalus, with any of the following ICD-10 codes were included in the study: Malformations of the aqueduct of Sylvius (Q03.0); Atresia of foramina of Magendie and Luschka, also called Dandy-Walker syndrome (Q03.1); other specified types of congenital hydrocephalus (Q03.8); and unspecified congenital hydrocephalus (Q03.9). Based on whether accompanied by additional malformations in other systems or organs, $\mathrm{CH}$ cases were divided into two subgroups: isolated $\mathrm{CH}$ and associated $\mathrm{CH}[7,9]$.

Maternal age $(<20,20-24,25-29,30-34, \geq 35$ years), residential area (urban, rural), gender, and plurality of pregnancy were obtained for all births and $\mathrm{CH}$ cases. Residential areas were classified into urban (cities and towns) and rural (villages and countryside) areas based on mother's last residence address where she lived for at least 1 year [20]. Birth weight $(<2500,2500-3999, \geq 4000 \mathrm{~g})$, gestational age $(28-36,37-41, \geq 42$ weeks), perinatal outcomes (stillbirth, early neonate death and alive within 7 days), and time of diagnosis were acquired for $\mathrm{CH}$ cases.

\section{Statistical analysis}

The prevalence of $\mathrm{CH}$ was calculated as the number of $\mathrm{CH}$ cases, divided by the total number of live birth and stillbirth in CBDMN database during the 8-year period of the study. The changes in prevalence over the study period were analyzed by linear chi-square test [22]. $\mathrm{CH}$ prevalence stratified by maternal age, residential area, gender and plurality of pregnancy were compared by calculating prevalence ratios (PR) and 95\% confidence intervals $(95 \% \mathrm{CI})$ with Poisson regression model. All statistical analyses were performed with SPSS 21 . The statistical significance level for $\alpha$ was set at 0.05 .

\section{Results}

During the study period, a total of $6490 \mathrm{CH}$ cases (5245 isolated and 1245 associated cases) were identified among 10,574,061 births, yielding a prevalence of 6.14 , 4.96, and 1.18 per 10,000 births for the overall, isolated, and associated $\mathrm{CH}$, respectively. There was a downward 
trend in the annual prevalence of overall $\mathrm{CH}$ (from 7.52 to 5.98 per 10,000 births, $P<0.001$ ) and isolated $\mathrm{CH}$ (from 6.17 to 4.19 per 10,000 births, $P<0.001$ ), but not in the prevalence of associated $\mathrm{CH}$ (Fig. 1).

The prevalence of isolated and associated $\mathrm{CH}$ varied significantly between groups stratified by maternal age, residential area, gender and plurality of pregnancy (Table 1). Both younger and older maternal age were associated with higher $\mathrm{CH}$ prevalence as compared to the maternal age group of 20-24 years. The highest prevalence of isolated $\mathrm{CH}$ was observed in maternal age $<20$ years group (PR: $1.88,95 \%$ CI: $1.60-2.22$ ), whereas the highest prevalence of associated $\mathrm{CH}$ was in $\geq 35$ years maternal age group (PR: 1.98, 95\% CI: 1.67-2.36). Higher prevalence was also found in infants born to mothers who resided in rural areas (PR: 1.40, 95\% CI: 1.34-1.48), infants with male sex (PR: 1.12, 95\% CI: 1.06-1.17), and multiple births (PR: 2.55, 95\% CI: $2.25-2.90)$.

Among $6490 \mathrm{CH}$ cases, 5737 (88.47\%) cases were diagnosed prenatally, $4942(76.15 \%)$ cases were terminations of pregnancy (TOP). Characteristics of 1548 nonaborted $\mathrm{CH}$ cases were shown in Table 2, the low birth weight rate of associated $\mathrm{CH}$ was higher than that of isolated $\mathrm{CH}$ (45.98\% vs $35.82 \%)$. Of infants affected by $\mathrm{CH}, 37.53 \%$ were born prematurely. The total stillbirth rate of $\mathrm{CH}$ was $34.35 \%$. The early neonatal mortality rates (ENMR) were 17.93\% (135/753), 28.63\% (75/262) and $20.69 \%(210 / 1015)$ for the isolated, associated and overall hydrocephalus, respectively. ENMR of $\mathrm{CH}$ in rural area $(141 / 578,24.39 \%)$ was significantly higher than that in urban area $(69 / 437,15.79 \%)$.

\section{Discussion}

By analyzing almost 10 million birth data in CBDMN, we identified an overall prevalence of $6.14 / 10,000$ for $\mathrm{CH}$ during 2005 to 2012, which was significantly lower than the rate of 7.03/10,000 during 1996-2004 $(P<0.001)$ [14]. The overall rate in our study also

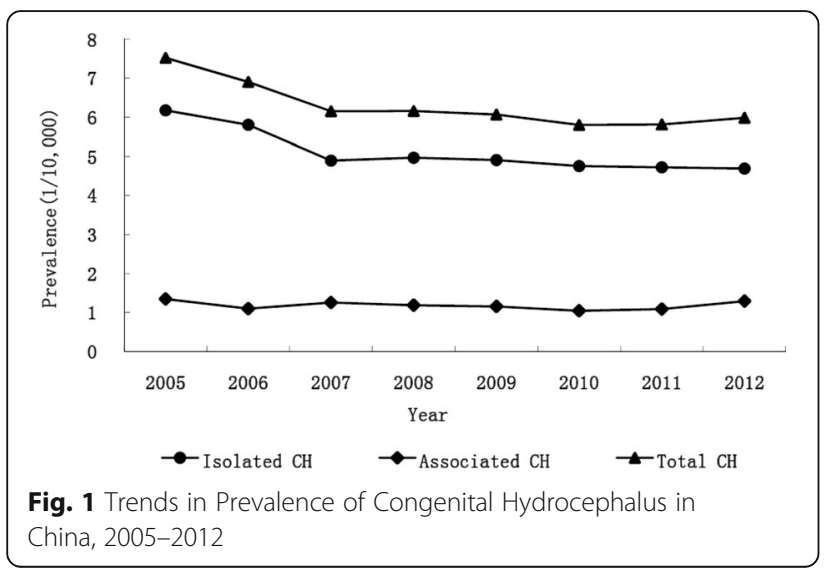

appeared lower than those from previous studies conducted in mainland China (6.9-9.2/10,000) [11-13]. In comparison with some ICBDSR member programs with the same $\mathrm{CH}$ inclusion criterion, our prevalence was comparable to that in United Kingdom-Wales $(6.43 / 10,000)$, higher than that in Canada (4.84/ $10,000)$, and lower than that in USA-Texas $(7.88 /$ 10,000), Japan $(7.81 / 10,000)$ and India $(7.24 / 10,000)$ [21]. Notably, all the above-mentioned ICBDSR programs include cases or terminations of pregnancy less than 28 weeks of gestation, so the estimated prevalence could be higher than the current observation if $\mathrm{CH}$ cases of any gestational age were included in CBDMN. Previous study in California showed that Asian populations had the lowest $\mathrm{CH}$ prevalence, followed by Caucasians and Hispanics, and then Blacks [8]. The prevalence in the current study was higher than those reported in Caucasians in United States $(5.4 / 10,000)$ [8] and several European regions $(4.65 / 10,000)$ [7], but lower than those found in Sweden $(6.6 / 10,000)$ [10] and Denmark $(11.3 / 10,000)$ [9]. The considerable variations in previous studies may be explained by several factors such as ethnicity, socioeconomic factors, different case inclusion criterions, etc.

Similar to previous findings of studies in the United States [8], Sweden [10], as well as a few provinces of China [12, 13], a downward trend in $\mathrm{CH}$ prevalence was obtained in our study, which seemed to reverse an earlier upward trend from 1996 to 2004 from the same data source (CBDMN) [14]. In the United States a great decline was found in the prevalence of $\mathrm{CH}$ cases accompanied by NTDs, which was thought to be related with folic acid supplementation [23]. Since $\mathrm{CH}$ cases with NTDs were excluded in the current analysis, the inverse trend during recent 8-year period cannot be explained by specific interventions related to NTDs. Meanwhile, several studies in mainland China suggested that downward trend in $\mathrm{CH}$ prevalence was associated with the widely implementation of prenatal diagnosis service, which has been boosted by the National Regulation on the Administration of Prenatal Diagnosis Techniques since 2003. According to the regulation, pregnant women are recommended to have systemic ultrasound examination to screen for birth defects in the second trimester, and pregnancy affected by severe birth defects is legally allowed to be terminated through a standardized process. Reasonably, a portion of fetuses with severe hydrocephalus could be diagnosed and terminated before 28 weeks of gestation along with the widespread use of prenatal sonography, which might result in the decrease of $\mathrm{CH}$ prevalence to some extent. Nevertheless, the contribution of improved maternal nutrition status and prenatal health care should not be neglected. 
Table 1 Prevalence of congenital hydrocephalus (1/10,000) in China during 2005-2012, stratified by maternal age, residential area, gender, and plurality of pregnancy

\begin{tabular}{|c|c|c|c|c|c|c|c|c|c|c|}
\hline & \multirow{2}{*}{$\begin{array}{l}\text { Number } \\
\text { of Births }\end{array}$} & \multicolumn{3}{|c|}{ Isolated CH $(N=5245)$} & \multicolumn{3}{|c|}{ Associated CH $(N=1245)$} & \multicolumn{3}{|c|}{ Total CH $(N=6490)$} \\
\hline & & Number & $\begin{array}{l}\text { Prevalence } \\
(95 \% \mathrm{Cl})\end{array}$ & $\begin{array}{l}\text { PR } \\
(95 \% \mathrm{Cl})\end{array}$ & Number & $\begin{array}{l}\text { Prevalence } \\
(95 \% \mathrm{Cl})\end{array}$ & $\begin{array}{l}\text { PR } \\
(95 \% \mathrm{Cl})\end{array}$ & Number & $\begin{array}{l}\text { Prevalence } \\
(95 \% \mathrm{Cl})\end{array}$ & $\begin{array}{l}\text { PR } \\
(95 \% \mathrm{Cl})\end{array}$ \\
\hline \multicolumn{11}{|c|}{ Maternal age (years) ${ }^{a}$} \\
\hline$<20$ & 196,160 & 155 & $7.90(6.66-9.15)$ & $\begin{array}{l}1.88(1.60- \\
2.22)\end{array}$ & 29 & $1.48(0.94-2.02)$ & $\begin{array}{l}1.50(1.03- \\
2.18)\end{array}$ & 184 & $\begin{array}{l}9.38(8.02- \\
10.74)\end{array}$ & $\begin{array}{l}1.81(1.56- \\
2.10)\end{array}$ \\
\hline $20-24$ & $2,764,522$ & 1677 & $6.07(5.78-6.36)$ & $\begin{array}{l}1.45(1.35- \\
1.54)\end{array}$ & 314 & $1.14(1.01-1.26)$ & $\begin{array}{l}1.15(1.00- \\
1.33)\end{array}$ & 1991 & $7.20(6.89-7.52)$ & $\begin{array}{l}1.39(1.31- \\
1.48)\end{array}$ \\
\hline $25-29$ & $4,435,764$ & 1863 & $4.20(4.01-4.39)$ & 1.00 (ref) & 438 & $0.99(0.89-1.08)$ & 1.00 (ref) & 2301 & $5.19(4.98-5.40)$ & 1.00 (ref) \\
\hline $30-34$ & $2,233,043$ & 1008 & $4.51(4.24-4.79)$ & $\begin{array}{l}1.08(1.00- \\
1.16)\end{array}$ & 279 & $1.25(1.10-1.40)$ & $\begin{array}{l}1.27(1.09- \\
1.47)\end{array}$ & 1287 & $5.76(5.45-6.08)$ & $\begin{array}{l}1.11(1.04- \\
1.19)\end{array}$ \\
\hline$\geq 35$ & 944,572 & 540 & $5.72(5.23-6.20)$ & $\begin{array}{l}1.36(1.24- \\
1.50)\end{array}$ & 185 & $1.96(1.68-2.24)$ & $\begin{array}{l}1.98(1.67- \\
2.36)\end{array}$ & 725 & $7.68(7.12-8.23)$ & $\begin{array}{l}1.48(1.36- \\
1.61)\end{array}$ \\
\hline \multicolumn{11}{|c|}{ Residential area ${ }^{\mathrm{b}}$} \\
\hline Urban & $5,630,037$ & 2323 & $4.13(3.96-4.29)$ & 1.00 (ref) & 582 & $1.03(0.95-1.12)$ & 1.00 (ref) & 2905 & $5.16(4.97-5.35)$ & 1.00 (ref) \\
\hline Rural & $4,944,024$ & 2920 & $5.91(5.69-6.12)$ & $\begin{array}{l}1.43(1.36- \\
1.51)\end{array}$ & 662 & $1.34(1.24-1.44)$ & $\begin{array}{l}1.30(1.16- \\
1.45)\end{array}$ & 3582 & $7.25(7.01-7.48)$ & $\begin{array}{l}1.40(1.34- \\
1.48)\end{array}$ \\
\hline \multicolumn{11}{|l|}{ Gender $^{c}$} \\
\hline Female & $4,940,848$ & 2323 & $4.70(4.51-4.89)$ & 1.00 (ref) & 513 & $1.04(0.95-1.13)$ & 1.00 (ref) & 2836 & $5.74(5.53-5.95)$ & 1.00 (ref) \\
\hline Male & $5,630,497$ & 2906 & $5.16(4.97-5.35)$ & $\begin{array}{l}1.10(1.04- \\
1.16)\end{array}$ & 703 & $1.25(1.16-1.34)$ & $\begin{array}{l}1.20(1.07- \\
1.35)\end{array}$ & 3609 & $6.41(6.20-6.62)$ & $\begin{array}{l}1.12(1.06- \\
1.17)\end{array}$ \\
\hline \multicolumn{11}{|c|}{ Plurality of pregnancy ${ }^{d}$} \\
\hline Singleton & $10,412,509$ & 5051 & $4.85(4.72-4.98)$ & 1.00 (ref) & 1190 & $1.14(1.08-1.21)$ & 1.00 (ref) & 6241 & $5.99(5.85-6.14)$ & 1.00 (ref) \\
\hline Multiple & 161,552 & 192 & $\begin{array}{l}11.88(10.20- \\
13.57)\end{array}$ & $\begin{array}{l}2.45(2.12- \\
2.83)\end{array}$ & 55 & $3.40(2.50-4.30)$ & $\begin{array}{l}2.98(2.27- \\
3.91)\end{array}$ & 247 & $\begin{array}{l}15.29(13.38- \\
17.20)\end{array}$ & $\begin{array}{l}2.55(2.25- \\
2.90)\end{array}$ \\
\hline
\end{tabular}

Abbreviations: $\mathrm{Cl}$ Confidence interval, $P R$ Prevalence ratio, Ref Reference

${ }^{a} 2$ cases with unspecified maternal age were excluded; ${ }^{b} 3$ cases with unspecified residential area were excluded; ${ }^{c} 40$ cases with unknown gender and 5 cases with unspecified gender were excluded; ${ }^{d} 2$ cases with unspecified plurality of pregnancy were excluded

Values in bold represent statistical significance at a $95 \%$ confidence level

Table 2 Characteristics of 1548 non-aborted cases with congenital hydrocephalus

\begin{tabular}{|c|c|c|c|c|c|c|}
\hline & \multicolumn{2}{|c|}{$\begin{array}{l}\text { Isolated } \mathrm{CH} \\
(N=1201)\end{array}$} & \multicolumn{2}{|c|}{$\begin{array}{l}\text { Associated CH } \\
(N=347)\end{array}$} & \multicolumn{2}{|c|}{$\begin{array}{l}\text { Total CH } \\
(N=1548) \\
\end{array}$} \\
\hline & Number & Percent & Number & Percent & Number & Percent \\
\hline \multicolumn{7}{|l|}{ Birth weight $(g)^{a}$} \\
\hline$<2500$ & 428 & 35.82 & 160 & 45.98 & 588 & 38.11 \\
\hline 2500-3999 & 705 & 59.00 & 173 & 49.71 & 878 & 56.90 \\
\hline$\geq 4000$ & 62 & 5.19 & 15 & 4.31 & 77 & 4.99 \\
\hline \multicolumn{7}{|l|}{ Gestational age (weeks) } \\
\hline $28-36$ & 447 & 37.22 & 134 & 38.62 & 581 & 37.53 \\
\hline $37-41$ & 724 & 60.28 & 204 & 58.79 & 928 & 59.95 \\
\hline$\geq 42$ & 30 & 2.50 & 9 & 2.59 & 39 & 2.52 \\
\hline \multicolumn{7}{|l|}{ Perinatal outcome ${ }^{b}$} \\
\hline Live birth & 753 & 62.91 & 262 & 75.07 & 1015 & 65.65 \\
\hline Alive within 7 days & 618 & 51.63 & 187 & 53.58 & 805 & 52.07 \\
\hline Early neonate death & 135 & 11.28 & 75 & 21.49 & 210 & 13.58 \\
\hline Stillbirth & 444 & 37.09 & 87 & 24.93 & 531 & 34.35 \\
\hline
\end{tabular}

$\mathbf{a}_{5}$ cases with missing birth weight were excluded; ${ }^{\mathbf{b}} 2$ cases with missing perinatal outcome were excluded 
In the current study, higher prevalence was found in both younger ( $<20$ years) and advanced ( $\geq 35$ years) maternal age groups. Data from Czech Republic showed that significantly higher risk of hydrocephalus was in women above 37 years of age [24]. A Denmark study indicated that mothers under the age of 20 were more likely to have offspring with isolated hydrocephalus than those aged 25 to 34 years [9]. The U-shaped maternal-age distribution of $\mathrm{CH}$ prevalence highlighted maternal age as a risk factor of $\mathrm{CH}$ though the underlying cause was still unknown.

There are substantial urban-rural differences in the residents' education level, health literacy, occupational exposure, lifestyle, and access to health care in China [25]. The observed urban-rural variations in this study indicated that poor socioeconomic levels and individual health status were associated with increased $\mathrm{CH}$ risk. The male predominance in $\mathrm{CH}$ prevalence was consistent with previous studies [810], the underlying causes remain unclear although $\mathrm{X}$-linked genetic factors can explain a small portion of cases [3]. Previous findings in the United States demonstrated that the $\mathrm{CH}$ prevalence of multiple births increased to three times as compared to singletons $(23.08 / 10,000$ vs $7.07 / 10,000)$ [26]. Similar result was obtained in our study $(15.29 / 10,000$ vs $5.99 / 10,000)$.

In our study, about one third of non-aborted hydrocephalus cases were low birth weight and preterm births. Given that $\mathrm{CH}$ cases secondary to intraventricular haemorrhage were excluded from the current analysis, the high portion of low birth weight and preterm births are likely due to impaired physical development. In another word, though preterm birth is risk factor of neonatal hydrocephalus, congenital hydrocephalus may increase the risk of preterms. In low resource setting, $47.8 \%$ of severe hydrocephalus and $55.6 \%$ of Dandy-walker syndrome cases died prior to 1 year of age [27]. However, the neonatal mortality rate in our study was lower $(20.69 \%)$ due to the short monitoring period.

\section{Strengths and limitations}

Based on a large-sample-size database with extensive geographic coverage and good data quality management, our findings represent the current status of $\mathrm{CH}$ in Chinese population, which can provide valuable references for future intervention in China as well as in other developing countries. Considering the possible ascertainment bias due to variation in the diagnosis between different member hospitals and the short monitoring period, the observed $\mathrm{CH}$ prevalence and mortality rate in this study might be underestimated.
Due to data limitation, we can not make further causespecific analysis.

\section{Conclusions}

In conclusion, our analyses found a downward trend in birth prevalence of $\mathrm{CH}$ in China since 2005, and the prevalence varied significantly by maternal age, gender, residential area and plurality of pregnancy. The findings of relatively high prevalence and poor perinatal outcomes of infants with hydrocephalus are of great value for future study.

\section{Abbreviations}

CBDMN: Chinese Birth Defects Monitoring Network; CH: Congenital hydrocephalus; Cl: Confidence intervals; CSF: Cerebrospinal fluid; ENMR: Early neonatal mortality rate; ICBDSR: International Clearinghouse for Birth Defects Surveillance and Research; NTDs: Neural tube defects; PR: Prevalence ratios

\section{Acknowledgements}

The authors would like to thank the obstetricians, pediatricians, pathologists and other participants involved in the birth defects monitoring network. The content of this article is solely the responsibility of the authors and do not represent the official view of the National Center for Birth Defects Monitoring.

\section{Funding}

This project was supported by a grant from the National Natural Science Foundation of China (grant no. 81373069) and National Health and Family Planning Commission of China.

\section{Availability of data and materials}

The corresponding author obtained the permission to use the data for this analysis from the National Health and Family Planning Commission of China. The datasets used and analysed during the study are available from the corresponding author on reasonable request.

\section{Authors' contributions}

LY and CW performed statistical work and drafted the manuscript. LD designed research plan and revised manuscript. $C D, X L$ and $K D$ performed statistical work. YM, QL and YW checked and prepared data. JZ supervised birth defects surveillance program and provided data accession. All authors read and approved the final manuscript.

\section{Authors' information}

LY is a doctoral candidate at the West China School of Medicine, Sichuan University, mainly working on birth defects surveillance and birth defects epidemiology. CW is the leader of the Pediatric Department, mainly focusing on pediatrics. LD is the professor of the CBDMN, and concentrates on birth defects surveillance and epidemiology.

\section{Ethics approval}

Ethical approval was not necessary since the study was based on anonymised routine project monitoring data with no identifiable information on mothers. Permission was obtained from the National Health and Family Planning Commission of China to use the data for this analysis.

Consent for publication

Not applicable.

\section{Competing interests}

The authors declare that they have no competing interests.

\section{Publisher's Note}

Springer Nature remains neutral with regard to jurisdictional claims in published maps and institutional affiliations. 


\section{Author details}

National Center for Birth Defects Monitoring, West China Second University Hospital, Sichuan University, Sec.3 No.17, South RenMin Road, Chengdu, Sichuan 610041, China. ${ }^{2}$ Pediatric Department, West China Second University Hospital, Sichuan University, Chengdu, Sichuan, China.

Received: 1 March 2016 Accepted: 24 November 2017

Published online: 04 December 2017

\section{References}

1. James HE. Hydrocephalus in infancy and childhood. Am Fam Physician. 1992; 45(2):733-42

2. McAllister JP 2nd. Pathophysiology of congenital and neonatal hydrocephalus. Semin Fetal Neonatal Med. 2012;17(5):285-94.

3. Zhang J, Williams MA, Rigamonti D. Genetics of human hydrocephalus. J Neurol. 2006;253(10):1255-66.

4. Mataro M, Junque C, Poca MA, Sahuquillo J. Neuropsychological findings in congenital and acquired childhood hydrocephalus. Neuropsychol Rev. 2001;11(4):169-78.

5. Stoll C, Alembik Y, Dott B, Roth MP. An epidemiologic study of environmental and genetic factors in congenital hydrocephalus. Eur J Epidemiol. 1992:8(6):797-803.

6. Zajicek M, Gindes L, Hoffmann C, Morag I, Achiron R. Prenatal diagnosis of obstructive hydrocephalus associated with parvovirus b19 infection. Obstet Gynecol. 2010;116(Suppl 2):521-2.

7. Garne E, Loane M, Addor MC, Boyd PA, Barisic I, Dolk H. Congenital hydrocephalus-prevalence, prenatal diagnosis and outcome of pregnancy in four European regions. Eur J Paediatr Neurol. 2010;14(2):150-5.

8. Jeng S, Gupta N, Wrensch M, Zhao S, Wu YW. Prevalence of congenital hydrocephalus in California, 1991-2000. Pediatr Neurol. 2011;45(2):67-71.

9. Munch TN, Rasmussen ML, Wohlfahrt J, Juhler M, Melbye M. Risk factors for congenital hydrocephalus: a nationwide, register-based, cohort study. J Neurol Neurosurg Psychiatry. 2014;85(11):1253-9.

10. Persson EK, Anderson S, Wiklund LM, Uvebrant P. Hydrocephalus in children born in 1999-2002: epidemiology, outcome and ophthalmological findings. Childs Nerv Syst. 2007;23(10):1111-8.

11. Hu YH, Li LM, Li P. A five years surveillance on neural system birth defects in rural areas of China. Zhonghua Liu Xing Bing Xue Za Zhi. 1996;17(1):20-4.

12. Sun G, Xu ZM, Liang JF, Li L, Tang DX. Twelve-year prevalence of common neonatal congenital malformations in Zhejiang province, China. World J Pediatr. 2011;7(4):331-6.

13. Xia L, Sun L, Wang X, Yao M, Xu F, Cheng G, et al. Changes in the incidence of congenital anomalies in Henan Province, China, from 1997 to 2011. PLoS One. 2015;10(7):e0131874.

14. Dai L, Zhou GX, Miao L, Zhu J, Wang YP, Liang J. Prevalence analysis on congenital hydrocephalus in Chinese perinatal from 1996 to 2004 Zhonghua Yu Fang Yi Xue Za Zhi. 2006;40(3):180-3.

15. Xi B, Zhou C, Zhang M, Wang Y, Xu L. Maternal and child mortality in China. Lancet. 2014;383(9921):953-4

16. Bian XM, Guo Q, Qi QW. Current situation and development of prenatal diagnosis in China. Front Med China. 2010;4(3):271-4.

17. Zhu J, Li X, Wang Y, Mu D, Dai L, Zhou G, et al. Prevalence of neural tube defect pregnancies in China and the impact of gestational age of the births from 2006 to 2008: a hospital-based study. J Matern Fetal Neonatal Med. 2012;25(9):1730-4

18. Deng C, Yi L, Mu Y, Zhu J, Qin Y, Fan X, et al. Recent trends in the birth prevalence of down syndrome in China: impact of prenatal diagnosis and subsequent terminations. Prenat Diagn. 2015;35(4):311-8.

19. Dai L, Zhu J, Liang J, Wang YP, Wang H, Mao M. Birth defects surveillance in China. World J Pediatr. 2011;7(4):302-10.

20. Dai L, Zhu J, Mao M, Li Y, Deng Y, Wang $Y$, et al. Time trends in oral clefts in Chinese newborns: data from the Chinese National Birth Defects Monitoring Network. Birth Defects Res A Clin Mol Teratol. 2010; 88(1):41-7.

21. ICBDSR Office. Annual report 2013 with data for 2011. Roma: THE INTERNATIONAL CENTRE ON BIRTH DEFECTS-ICBDSR Centre; 2013. p. 31-216.

22. Agresti A. Inference for contingency tables. New York: Wiley; 2002. p. 70-114

23. Williams LJ, Mai CT, Edmonds LD, Shaw GM, Kirby RS, Hobbs CA, et al. Prevalence of spina bifida and anencephaly during the transition to mandatory folic acid fortification in the United States. Teratology. 2002;66(1):33-9.
24. Sipek A, Gregor V, Horacek J, Masatova D. Congenital hydrocephalus 1961 2000-incidence, prenatal diagnosis and prevalence based on maternal age. Ceska Gynekol. 2002;67(6):360-4.

25. Tang S, Meng Q, Chen L, Bekedam H, Evans T, Whitehead M. Tackling the challenges to health equity in China. Lancet. 2008;372(9648):1493-501.

26. Tang Y, Ma CX, Cui W, Chang V, Ariet M, Morse SB, et al. The risk of birth defects in multiple births: a population-based study. Matern Child Health J. 2006;10(1):75-81.

27. Kumar M, Sharma S, Bhagat M, Gupta U, Anand R, Puri A, et al. Postnatal outcome of congenital anomalies in low resource setting. Prenat Diagn. 2013:33(10):983-9.

\section{Submit your next manuscript to BioMed Central and we will help you at every step:}

- We accept pre-submission inquiries

- Our selector tool helps you to find the most relevant journal

- We provide round the clock customer support

- Convenient online submission

- Thorough peer review

- Inclusion in PubMed and all major indexing services

- Maximum visibility for your research

Submit your manuscript at www.biomedcentral.com/submit
Biomed Central 